\title{
Underneath the Observational Snapshot: Looking For Sense and Meaning Behind the First Impressions of a Learning Interaction
}

\author{
Sandra Rennie \\ Sequals \\ HUDCETT
}

\begin{abstract}
Education practitioners, including Ofsted inspectors and Teacher Educators, try to make sense of behaviour in the classroom by observing the interaction of teachers and learners. They make judgements about what is good teaching, what is bad learner behaviour and what are inclusive and effective learning experiences. This article argues that such observations are inadequate for assessing and evaluating learning behaviour and insufficient to enable teachers to develop their own personalised teaching and learning strategies and their confidence as professional teachers. The article was written in response to examples of Further Education (FE) teachers describing the college classroom as a war zone and a battlefield (Lebor, 2013). The author argues that such metaphors reinforce the notion that teachers and learners are situated at opposing sides of an education institution with differing interests. They also ignore the position of the teacher as being a learner too. The author advocates using an existentialist approach to understanding and reflecting on the learning process. She models strategies she has used herself to attempt to step outside the conventional paradigm of learning in college and create a new framework for reflecting on what is good behaviour from a teacher and good behaviour from a learner.
\end{abstract}

\section{Key words \\ Ofsted; Observation; Behaviour; Metaphors; Existentialist; Teaching; Learning; Model of Reflection; Personalised; Reflexive; Multi-modal; Thought Experiment.}

This article is written in a personalised writing style, using case studies personally experienced and a personal approach to reflective practice. The aim is to model how individual practising teachers and Teacher Educators could reflect on learning behaviour whilst considering their own personal narratives and the broader physical and social contexts of their work and academic theories. After reading Lebor's (2013) War and Peace in the Classroom, I was prompted to engage in a critical dialogue with the author on the subject of learner behaviour and that was my motivation for writing this article. I experienced a visceral distaste for the notion of describing our classrooms as war zones. This was not always the case for me as I too had used war metaphors in my earlier paper Stories From the Frontline (2003), written whilst employed as a teacher and manager at a large Further Education college. I have changed my understanding considerably since then and aim to share the history of how I did this. I will use the technique of reflecting on a case study to start with, as did the Lebor articles, but instead of looking at dramatic 'bad behaviour' (Lebor, 2013: p. 21) incidents in the everyday context of a college classroom, I have chosen to examine two minor, everyday incidents in the non-routine environment of a college (or school) trip. By stepping outside the quotidian it may become easier to challenge the argument that there are such essential notions as 'good' and 'bad' behaviour that everyone agrees on and to take a more existentialist approach to examining the interaction between students and teachers.

'A central feature of existentialism, therefore, is the critique of essentialism. If we are to develop a genuine and adequate understanding of the people we 
engage within our practice, we need to understand them in situation, as part of an evolving set of interactions, rather than as fixed entities.'

(Thompson and Pascal, 2011: p. 3)

The case study that follows is based on my own direct observation. In reflecting on the case study I aim to emulate the Open University's Health and Social Care faculty model:

'... whereby reflective practice is seen as a "synthesis of reflection, selfawareness and critical thinking" (Eby, 2000)'.

(Finlay, 2008: p.5)

To mitigate inevitable bias the case study is written in my own choice of words, in the present tense rather than an 'academic' style and is accompanied by a reflection on what this narrative means for me as a teacher continuously aiming to be a 'better' teacher. This personal reflection compares two observed, similar, real-life incidents and follows some of the ideas behind Brookfield's critical lenses model of reflection (1995). It also uses the metaphor of a flight of steps as an aid for memory and understanding, as explained thus:

'...due to the metaphor's ability to better convey correlations, parallels, likeness, significances and similarities of the message, a metaphor or story can be used to highlight potentially difficult or abstract ideas which may otherwise be difficult to comprehend'.

(Koralia, in Ashmore and Robinson, 2014: in print)

On a sunny day in June 2014 at the foot of the Whitby Abbey steps, two teachers display their different approaches to education. Looking through my lens as a Teacher Educator and a trained observer this is what I see: a harassed-looking Teacher A approaches the flight of steps and attempts to herd the straggling party of teenagers to the pavement at the side of the road, saying:

"How many times do I have to tell you to clear the road and let people pass?"

This rhetorical question creates an immediate dissonance - I can see the learners' defensive body language; furthermore it is an invitation to the bright student to answer facetiously, "33 times - Miss". The question is without direction and, to my view, it will confuse the student who needs clear instructions. They are words without explanation that will blank out the wishes of the student who wants to learn; what Teacher A says sounds to be without respect and so will alienate the students who want to be considered as being 'people' as well; people who are allowed a space and a place to be themselves. The school (or college?) party is lectured to by Teacher A and then starts off climbing the flight of steps; some students tapping on their phones as they go up and others pushing their way up through the crowds of tourists who are treading cautiously down the steep steps. I do not know what the students have learned from this interchange - except perhaps that they are a potential nuisance to people around them.

Teacher B now takes up exactly the same spot at the foot of the steps, he puts his hand up and his party of students gather round him to hear what he has to say. He asks the group:

"Who has been here before?" 
This carefully-framed question seems to create interest and harmony in the group. I watch as three students put their hands up and others bunch up closer to hear. He asks them to describe where they had been and what they thought was important to look out for. The students' previous stories are acknowledged, their opinions are sought and discussed, they cluster together to discuss a strategy for how they will approach their climb of the steps. From this I assume they learn facts, information, social skills, respect for each other, strategies for dealing with new situations and they learn that they are valued.

For this first stage of my reflection I wonder what might be the aims of the learning session. It may be that Teacher A sees her task is to pass on knowledge about history, or geology or whatever subject her students will be examined on in the future. If this is the case, she may believe that ensuring the students are not a danger to themselves or others is a side issue, a distraction and waste of time; albeit unavoidable. Teacher B may see his primary responsibility as one of preparing his students for future life or employment. In this case, his teaching strategies would aim to involve learners in problem solving, in looking around themselves, and in discussing their next steps. Thus, the task of climbing the flight of stairs safely becomes a group responsibility. I then move my reflection to considering aspects and functions of curriculum choices in general. The learning of life and social skills has been recognised as an important factor in improving behaviour in schools (Didaskalou and Millward, 2007). These skills have been taught and assessed in Further Education over the last couple of decades under various names including: the 'Wider Key Skills', 'Soft Skills', 'Transferable Skills' or even just 'Employability Skills'. I reflect on the difficulty I have experienced in teaching these skills and values as a separate subject when they were not embedded and reinforced in other parts of students' college life.

The second stage of reflection takes place a month later when I look at the snapshot photo I took minutes after these observed interactions and ponder over the significance of what the image represents.

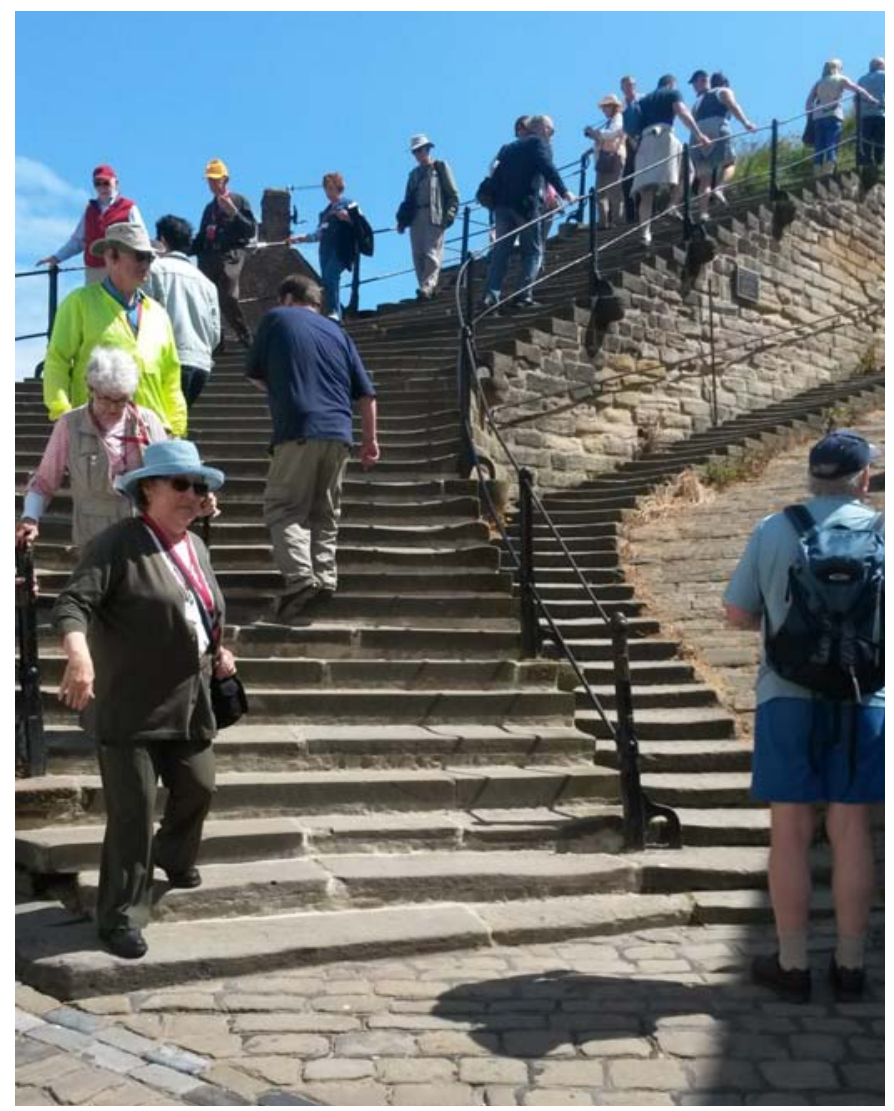


This photo makes me reflect on the learning that may have taken place because of the physical space of the interaction. The physical activity of walking up steps with other teachers and learners may have helped fix memories in the learners' minds. The long, precarious, and crowded flight of steps may provide them with a useful metaphor for future tasks that face them. The sunny weather seems to be significant, as do the hand rails and stone walls; all of which provide further metaphors to stimulate creative thoughts about learning.

It also seems important to identify the ways we could extract meaning from these two observed incidents. I could see that multimodal communication (Kress, 2010) was taking place in both of the interactions and I suspect that the learning is a result of many factors; not just what is said but also the way the whole message is communicated, where it is communicated, and by whom. The learning in both of these case studies occurs in different domains (cognitive, affective and psycho-motor domains) and at different levels of awareness (at a conscious, subconscious or subliminal level). The concepts and analytical framework of multi-modality are helpful in making sense of this.

'It (multimodality) focuses on analyzing and describing the full repertoire of meaning-making resources that people use (visual, spoken, gestural, written, three-dimensional, and others, depending on the domain of representation) in different contexts, and on developing means that show how these are organized to make meaning.'

(Bezemer, 2012: online)

The next stage of reflection involves attempting to identify how much of my own past experiences are directing and biasing my understanding of these incidents. I acknowledge that my lack of understanding of the participants' backgrounds means that my analysis of this holiday 'snapshot' observation is too simplistic. It focuses on evaluating the discourse - the words and the body language - there is no understanding of where the learners have come from and where they find themselves now. We do not know how far the students have travelled, both actually and metaphorically, to be present in front of us. It would be easy, but completely invidious and unfair, to say that, as a result of my observations, Teacher A is a 'bad' teacher and Teacher B is a 'good' teacher and that their students are exhibiting 'good' or 'bad' behaviour; but that is exactly the heuristic assessment I make at first.

After thinking this through, I realise that when I report an anecdote about learner behaviour I need to remember I am an outsider with an outsider's view; a bystander and an observer, not a participant with insight. I am not part of these learning experiences observed at the foot of the Whitby Abbey steps, so instead of judging the teachers' performances perhaps there is an alternative way to learn from my observations? I aim to be not just a reflective practitioner but a reflexive practitioner and a participant observer.

'Reflexive practitioners engage in critical self-reflection: reflecting critically on the impact of their own background, assumptions, positioning, feelings, behaviour while also attending to the impact of the wider organisational, discursive, ideological and political context.'

(Finlay, 2008: p. 6)

I experiment with developing a thought framework that would be easy to remember and apply and yet would take into account some of the tangle of meanings and modes of 
communication underlying a learning interaction. My ideas come from several sources but one thing they all have in common is they originate outside the daily work routine: playing with ideas I have read; going on holiday in Whitby; reflecting on books written by thinkers from other academic disciplines, for example an architect's view of education (Boys, 2011); reading the online discussions of teacher colleagues in the Think Differently Project and the Teach Different project; attending conferences at Northern College and the University of Huddersfield; and emailing the first draft of this article to other Teacher Educators to start a critical dialogue on the subject.

Defining my own thinking framework, rather than using a recognised checklist or conceptual framework, proves to be challenging. I want it to be simple but comprehensive and useful, and also to embrace insights from a variety of academic disciplines including philosophical, psychological, sociological, historical and geographical understandings. I decide to call this framework my four 'dimensions' of learning: Time, Space, Place and Narrative.

The Time dimension needs us to know where you are on your learning journey. Are you at the beginning of learning and are you starting out with excitement or trepidation or near the end and, if so, are you full of satisfaction or disillusionment? The Space dimension requires you to ask where your learning is happening. Is it outside in the open air, online in cyberspace, inside in a classroom, in a workshop or in the corridor and canteen spaces in between? Is your space crowded, comfortable or empty? Are you free to move randomly, are you guided or are you constrained within it? The Place dimension is the one which looks at how you are situated. What is the status of where you find yourself? Are you seen as important or not? Are you part of an organisation that values learning or not? Is the institution you are studying with valued by others? The Narrative dimension is about seeing each person's own story, what they value and what makes them get out of bed in the morning. What makes you learn new things and what makes you want to teach others? These can all be appreciated when we experience a learning interaction as a fourdimensional work of art rather than a superficial 'snapshot'.

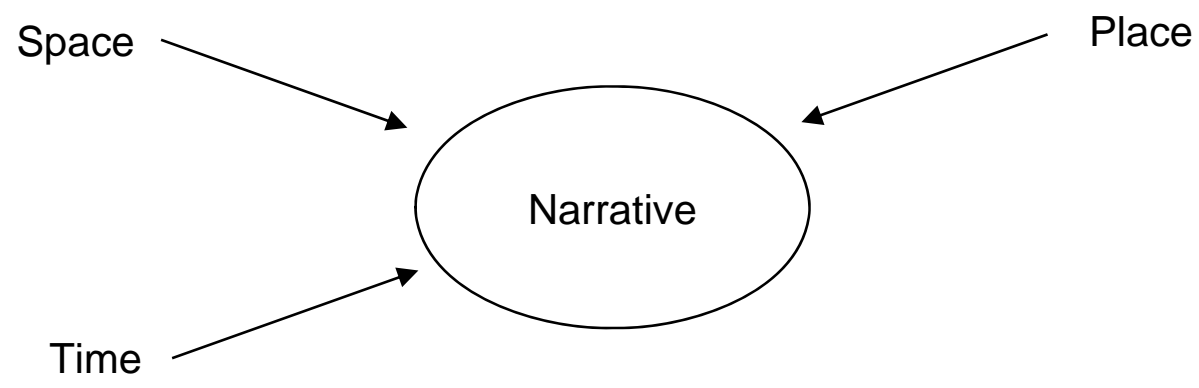

After developing the framework I rummage through the pile of teaching experiences in my memory and choose a critical incident from my own teaching to try out a thought experiment. The memory I select is one I had recorded a few weeks earlier in a reflective journal:

"In the role of a Teacher Educator I am conducting an evening class in a large, airy classroom, with a small group of six trainee teachers. They are halfway through their course and a group identity has gelled which feels a constructive and mutually supportive one. Four of the trainees independently, and at various times previously, have described themselves as 'hands-on' teachers. Some of them are already experienced teachers, some are new to teaching, some are in 
paid teaching work, some are in voluntary teaching, one is also managing teachers. I am giving a talk on 'Communication theory' and I am using what I consider to be a 'flashy' PowerPoint as it has video and audio recordings embedded. A trainee arrives late, part the way through my talk and goes to the refreshment table to help herself to coffee. Two others take advantage of the distraction and get up also and make themselves a drink. With half the class gone I look around me and abandon the lecture on communication theory - it is not 'communicating' and I suddenly become aware that inadvertently I am modelling 'how not to communicate'. I also realise that the three trainees standing at the other side of the room making their own drinks are modelling how to communicate dissatisfaction in a very 'hands-on' way".

I use my newly-developed, four dimensions of learning model and make notes thus:

Time: Learners are tired in the evening after a full day's work and find it difficult to concentrate on a lecture and presentation. Teachers with full timetables find it easier to pick up a PowerPoint made previously and re-use it to cover the information content of a session. It is a waste of time to use a PowerPoint on communication because it is failing to communicate what is required. Worse than that, it is communicating an incorrect message which will now have to be unlearned - wasting even more time for everyone. We need to find a learning approach that uses time more effectively.

Space: A learner has come into the room from outside part-way through the session and so has changed the group dynamic. There is plenty of room in the classroom and learners are accustomed and encouraged to move around in the environment so they feel at home and can make the space their own. The teacher could divide the class into pairs and could get the learners to move around the room using the smaller tables spread round the edges of the room. The videos and audio recordings are online in cyberspace and so could be heard later at home or at work, in a different time and place.

Place: The person who made the first cup of coffee is also a manager and is used to taking the lead. Two of the students are mandated learners - they need to attend the class and pass the course if they want to keep their jobs so they are trying hard to concentrate on the PowerPoint. Everyone present is both a teacher and a learner, and we slip in and out of each of these roles without noticing. When we are in the role of teacher, we expect people to pay attention to us because we are teachers. We could formally decide in the group to all become learners for a time and investigate communication theory, for example on the internet, and then we could become teachers and teach each other.

Narrative: All the students have taken part in an initial assessment of their motivation at the beginning of the course. Four have reported having good or mixed experiences of formal, academic education in the past. Two have had poor experiences of formal education and have described occasionally being made to feel "stupid" and "slow learners". All of the students have chosen to become teachers primarily because they enjoy their specialist subject and want to share it. Three of them want to help their learners to have better life chances. Four of the students enjoy the interaction with others in a group and two of the learners prefer learning interactions on a one-to-one basis. We could use stories from our past education experiences to explain to each other what good and bad communication experiences are like. 
The benefit of using this four-dimensional model for analysis of learning is that it reframes the issue raised in Lebor's question:

'What happens when the students refuse to cooperate or simply do not collude with the contractual/managerial expectations model of teaching?'

$$
\text { (Lebor, 2014: p. 3). }
$$

We no longer need to talk about 'good' and 'bad' teachers or co-operative and non-cooperative learners. Instead we can focus on the learning interchange that is taking place in front of us rather than on the teaching and learning 'behaviours'. Students and teachers do not have to be coerced to comply with teacher and '... managerial expectations' (Lebor, ibid). Instead they could be excited by the collective project of learning together and be accepted by each other as being 'present' (Kline, 2009: p. 15) in the room as who they really are. This four-dimensional model treats learning as an equal transaction with everyone teaching, learning, participating and contributing according to their ability. The model also allows for an analysis of the occasional disruptions to learning and the birth of creative and innovative ideas to help us to transcend these disruptions.

The metaphors used in this article have been chosen carefully to eschew references to battles. From my past experiences as a teacher, I have learned that battles are never won or lost, they are only ever rescheduled. Battles are also of little help in promoting and enjoying learning. Using force, threats or promises may limit behaviour in the short term but it does not lead to long-term attitudinal or behavioural change. For the work that I am engaged in today I find the most useful metaphors for a classroom are: play space, cultural canteen, garden, greenhouse, rehearsal room, practice space or artists' studio. I aim to select the language, metaphors and arguments that reflect my preferred values and principles as both a teacher and learner. As yet I am unsure whether these metaphors would apply to all subjects, to all learning interchanges and to all the organisational cultures we may encounter in educational institutions. I would argue however that we need to consciously change the words, pictures and stories we use if we want to enthuse others with a love of learning. As teachers aiming to nurture our own love of learning we also need to discuss and develop our own personal analysis frameworks and participate in learning conversations with colleagues and others rather than simply appropriate and use those of established academic authorities.

\section{References}

Ashmore, L., Robinson, D. (2014) Learning, Teaching and Development Strategies for Action. Sage (in print).

Bezemer, J. (2012) 'What is Multimodality?' Institute of Education, University of London [online] http://mode.ioe.ac.uk/2012/02/16/what-is-multimodality/ [accessed 6 July 2014].

Boys, J. (2011) Towards Creative Learning Spaces. Routledge: London.

Brookfield, S. (1995) Becoming a Critically Reflective Teacher. San Francisco: Jossey Bass.

Didaskalou, E., Millward, A. (2007) 'Rethinking Assessment: Managing Behaviour and Reducing Disaffection'. Emotional and Behavioural Difficulties Vol. 12, No. 3, pp. 191-203. http://dx.doi.org/10.1080/13632750701489949

Finlay, L. (2008) 'Reflecting on "Reflective Practice"' PBPL paper 52 [online] www.open.ac.uk/pbpl [accessed 6 July 2014]. 
Kline, N. (2009) Time to Think, Listening to Ignite the Human Mind. Octopus Publishing: London.

Kress, G. (2010) Multimodality, a Social Semiotic Approach to Contemporary Communication. Taylor and Francis: Oxon.

Lebor, M. (2013) 'War and Peace in the Classroom: Moments of Reprieve; a Strategy for Reflecting on - and Improving Students' Classroom Behaviour'. Teaching in Lifelong Learning Vol. 5, No. 2, pp.12-21. http://dx.doi.org/10.5920/till.2013.5121

Lebor, M. (2014) 'War Stories; How Experienced Teachers Said They Responded To Disruptive Students In The Lifelong Learning Sector'. Teaching in Lifelong Learning Vol. 5, No. 2, pp. 12-21. http://dx.doi.org/10.5920/till.2014.5212

Rennie, S (2003) Stories From the Frontline: The Impact of Inspection on Practitioners. Learning and Skills Development Agency: London.

Thompson, N., Pascal, J. (2011) 'Reflective Practice: an Existentialist Perspective'. Reflective Practice: International and Multidisciplinary Perspectives Vol. 12, No. 1, pp. 15-26. http://dx.doi.org/10.1080/14623943.2011.541089

\section{Further Reading}

\section{Conferences}

What is Vocational Pedagogy 27 June 2014 http://consortium.hud.ac.uk/

Teach Different 4 July 2014 http://teachnorthern.wordpress.com/

\section{Projects}

Teach Different: The Reflexion Programme (Northern College) ETF funded Joint Practice Development Project 2014

Thinking Differently (WEA) ETF funded Joint Practice Development Project 2014 